\title{
Desenvolvimento pluridimensional e a Agenda 2030: limites e possibilidades à efetivação do consumo sustentável na era "da leveza"
}

\author{
Tuana Paula Lavall ${ }^{1}$ \\ Giovanni Olsson ${ }^{2}$
}

\begin{abstract}
RESUMO
O artigo analisa quais os limites e possibilidades à efetivação do consumo sustentável, pontuado como um dos objetivos da Agenda 2030 das Organização das Nações Unidas (ONU), na era "da leveza", conceito elaborado pelo filósofo Gilles Lipovetsky para descrever a sociedade de consumo contemporânea. De forma específica, explora os aspectos centrais da construção da Agenda 2030 pela ONU; apresenta qual a inserção do consumo sustentável no mencionado documento; e caracteriza os paradoxos do consumo na denominada "sociedade da leveza". Com o emprego do método dedutivo e utilizando as técnicas de pesquisa bibliográfica e documental, o estudo, que é de cunho teórico e de caráter qualitativo, ensaia uma aproximação entre o paradigma de desenvolvimento endossado pelos países-membro da ONU e as teorizações sobre a cultura do consumo, destacadamente aquelas procedidas por Gilles Lipovetsky. A conclusão é no sentido de que, embora a promoção do consumo sustentável encontre limites na própria tessitura social contemporânea, marcada pelo consumismo, apego ao novo e desperdício, emergem tendências como o consumo ecológico, o comércio justo e o consumo compartilhado, que se apresentam como possibilidades para a efetivação do consumo sustentável.
\end{abstract}

Palavras-chave: desenvolvimento pluridimensional; Agenda 2030; consumo sustentável; sociedade da leveza.

\section{Multidimensional development and the 2030 Agenda: limits and possibilities for implementing sustainable consumption in the "lightness" era}

\begin{abstract}
The article analyzes what are the limits and possibilities of realizing sustainable consumption, punctuated as one of the objectives of the 2030 Agenda of the United Nations (UN), in the era of lightness, a concept elaborated by the philosopher Gilles Lipovetsky to describe the consumer society contemporary. Specifically, it explores the central aspects of the UN's construction of Agenda 2030; presents which insertion of sustainable consumption in the document; and make up the consumption paradoxes called "society of lightness". With the use of the deductive method and the use as techniques of bibliographic and documentary research, study, which is a theoretical and qualitative method, teaches an approach between the development paradigm endorsed by UN member countries and how publications on culture consumption, especially those carried out by Gilles Lipovetsky. The conclusion is meaningless, although the promotion of sustainable consumption finds limits in the contemporary social itself, marked by consumption, attachment to the new and desperate, emerging trends such as ecological consumption, fair trade and shared consumption, which present themselves as possibilities for realizing consumption sustainable. Key-words: multidimensional development; Agenda 2030; sustainable consumption; lightness society.
\end{abstract}

\section{INTRODUÇÃO}

O consumo é variável determinante para a promoção do desenvolvimento sustentável, haja vista os impactos ambientais e sociais que dele decorrem. Não por acaso, as estratégias de

\footnotetext{
${ }^{1}$ Mestranda em Direito na Universidade Comunitária da Região de Chapecó. Bolsista da CAPES/PROSUC, na modalidade integral. Bacharela em Direito pela Unochapecó. E-mail: tuanalavall@ unochapeco.edu.br

${ }^{2}$ Professor do Programa de Pós-Graduação stricto sensu em Direito da Unochapecó. Doutor e Mestre em Direito pela Universidade Federal de Santa Catarina (UFSC). E-mail: golsson71@ gmail.com
} 
enfrentamento das crises que ameaçam o futuro da humanidade, a exemplo da Agenda 2030 da Organização das Nações Unidas (ONU), apontam para a necessidade de mudança nos atuais padrões de consumo.

Nessa perspectiva, e tendo como ponto de partida as contribuições de Gilles Lipovetsky sobre sociedade de consumo hodierna, o presente trabalho objetiva analisar quais os limites e possibilidades à efetivação do consumo sustentável, pontuado como um dos objetivos da agenda de desenvolvimento da ONU para o período pós-2015, na era "da leveza" - conceito desenvolvido pelo autor. Especificamente, pretende-se apontar os aspectos centrais da construção da Agenda 2030 pela ONU; apresentar qual a inserção do consumo sustentável no mencionado documento; e caracterizar os paradoxos do consumo na sociedade da leveza.

A pesquisa encontra-se estruturada em três partes, articuladas entre si e associadas com os objetivos específicos. Inicialmente, trata da virada hermenêutica sofrida pelo conceito de desenvolvimento, enfatizando a abordagem de equilíbrio de plúrimas dimensões, proposta na Agenda 2030. Na sequência, explora o consumo sustentável, conceituando-o e situando-o como um dos Objetivos de Desenvolvimento Sustentável (ODS). Por fim, e ao apresentar a ideia de "leveza" em Lipovetsky (2016), focaliza os desafios da efetivação do consumo sustentável na sociedade contemporânea.

\section{PROCEDIMENTOS METODOLÓGICOS}

Do ponto de vista metodológico, o artigo relata pesquisa de cunho estritamente teórico, que ensaia uma aproximação entre o paradigma de desenvolvimento endossado pelos países membros da ONU, na Agenda 2030, e as teorizações contemporâneas sobre a cultura do consumo. Os objetivos são abordados desde uma perspectiva qualitativa, baseada na interpretação dos fenômenos e sem a pretensão de realizar medições numéricas.

Lança-se mão do método de procedimento dedutivo, mediante o qual, premissas mais gerais conduzem a ilações particulares. Nessa perspectiva, partindo-se de uma generalização reconhecida como verdadeira no âmbito do trabalho - a de que o consumo, na sociedade contemporânea, é marcado pela "leveza" -, chega-se, por meio de proposições logicamente relacionadas, a conclusões particulares - a respeito das (im)possibilidades da promoção do consumo sustentável na mencionada conjuntura sociocultural. Tal percurso interpretativo é orientado pela concepção construtivista social, com a atribuição de significados e a análise crítica do objeto estudado (CRESWELL, 2010). 
No tocante às técnicas, são empregadas as da pesquisa bibliográfica, com aporte na literatura especializada, publicada em livros e artigos científicos; e documental, com consulta a materiais que não receberam tratamento analítico, como documentos oficiais, declarações internacionais, e relatórios de organizações internacionais.

O trabalho adota como marco teórico as considerações sobre a sociedade de consumo formuladas por Gilles Lipovetsky nas obras "Felicidade paradoxal: ensaio sobre a sociedade do hiperconsumo" (2007), "O império do efềmero: a moda e seu destino nas sociedades modernas" (2009), e a "Da leveza: rumo à civilização sem peso" (2016), com enfoque no conceito de "civilização da leveza", cunhado pelo autor. A escolha deste referencial deve-se à sua capacidade de articular duas tendências paradoxais presentes nos padrões de consumo contemporâneos: de um lado, o apreço pela novidade e a frivolidade como valores dominantes, o que caracteriza a leveza; e, de outro, a tomada de consciência sobre essa mesma leveza e a emergência de tendências que problematizam o ato de consumir.

\section{DESENVOLVIMENTO PLURIDIMENSIONAL E A CONSTRUÇÃO DA AGENDA 2030 DA ONU}

Nos últimos setenta anos, o conceito de desenvolvimento ganhou notoriedade nos círculos acadêmicos e institucionais, e, tal como a ideia de progresso no século XIX, passou a desempenhar o papel de projeto civilizatório por meio do qual o mundo recém saído da Segunda Guerra Mundial esperançava alcançar a prosperidade e pôr fim a problemas antigos, como os conflitos bélicos sucessivos, o desemprego, a miséria, e as desigualdades políticas, econômicas e sociais.

O caminho adotado para alcançar o desenvolvimento, no entanto, foi o da expansão irrestrita do pilar econômico da sociedade, solapando-se as vastas possibilidades suscitadas pela ideia de desenvolvimento em prol de uma abordagem quantitativa. Conforme da Veiga (2005, p. 243), boa parte da literatura econômica da segunda metade do século XX alçava o enriquecimento como o promotor espontâneo da melhoria dos padrões sociais, sem considerar a existência de uma relação mais complexa, marcada pela intervenção de interesses políticos capazes de conferir diferentes rumos ao crescimento, com efeitos heterogêneos na estrutura social.

Generalizou-se, então, a crença de que o desenvolvimento econômico, como vinha sendo praticado pelos países que estiveram à frente da Revolução Industrial, poderia tornar-se 
universal (FURTADO, 1974, p. 16), e que os eventuais desequilíbrios ambientais, decorrentes das políticas de aceleração do crescimento, seriam sanados posteriormente, quando os países em desenvolvimento conseguissem reproduzir a renda per capita dos países desenvolvidos (SACHS, 2009, p. 50-51).

Essa abordagem unidimensional do desenvolvimento, porém, não demorou a encontrar resistências e mostrar suas contradições. Na década de 1970, com base no relatório "Os limites do crescimento", elaborado por um grupo interdisciplinar de estudiosos do Instituto de Tecnologia de Massachusetts (MIT), movimentos pró-meio ambiente passaram a mostrar o descompasso entre o discurso desenvolvimentista e a finitude dos recursos naturais. Forjar uma dimensão ambiental do desenvolvimento, no sentido de conter o seu ímpeto, era, agora, politicamente desejável, e, pensando nisso, a ONU criou, no início dos anos 1980, a Comissão Mundial sobre Meio Ambiente e Desenvolvimento, imbuída de "[...] conciliar a preocupação com a proteção ambiental com o desejo de desenvolvimento econômico no Sul e crescimento econômico no Norte [...]" (DRESNER, 2002, p. 35).

Enquanto impulsionadora de um conceito de desenvolvimento mais integral, a Organização também reconheceu, por meio de uma Declaração, em 1986, o desenvolvimento como direito humano. Conforme assinala Piovesan (2010, p. 102), o documento definiu desenvolvimento como o processo econômico, social, cultural e político, "com o objetivo de assegurar a constante melhoria do bem-estar da população e dos indivíduos, com base em sua ativa, livre e significativa participação neste processo, orientada pela justa distribuição dos benefícios dele resultantes".

A Declaração de 1986 contribuiu, portanto, para transformar, em pelo menos dois sentidos, a noção que se tinha sobre o desenvolvimento. Primeiro, alargou o seu conceito, ao demarcar, especialmente, a existência das dimensões social, cultural e política; e, segundo, atribui-lhe um viés individual, e, ao transformá-lo em direito subjetivo, jogou luz sobre a questão do desenvolvimento humano ${ }^{3}$.

Por outro lado, encarado como fenômeno de avanço coletivo em direção a melhores condições de vida, o desenvolvimento continuava a pressupor, na assertiva de Perrone-Moisés

\footnotetext{
${ }^{3}$ Nessa perspectiva, conforme a análise de Amartya Sen (2010, p. 20), o desenvolvimento "atenta-se particularmente para a expansão das 'capacidades' das pessoas de levar o tipo de vida que elas valorizam - e com razão", no sentido de que "o que as pessoas conseguem realizar é influenciado por oportunidades econômicas, liberdades políticas, poderes sociais e por condições habilitadoras, como boa saúde, educação básica e incentivo e aperfeiçoamento de iniciativas" (SEN, 2010, pág. 18). A concepção de desenvolvimento de Sen repercutiu, inclusive, na criação do Índice de Desenvolvimento Humano (IDH), no âmbito do Programa das Nações Unidas para o Desenvolvimento (PNUD), em 1990, como medida alternativa de desenvolvimento, em contraponto ao mero uso do Produto Interno Bruto (PIB).
} 
(1999, p. 190), a verificação de uma dupla espacialidade: o desenvolvimento como objeto de estratégia nacional e o desenvolvimento como objeto de estratégia internacional. No primeiro caso, tinha lugar a complexa questão dos modelos de desenvolvimento, que suscitava, entre outros debates, aquele acerca da pertinência da exportação de modelos de desenvolvimento pelos países desenvolvidos ou de sua hegemonia (PERRONE-MOISÉS, 1999, p. 190). No tocante à estratégia internacional, a autora atenta para o fato de que o desenvolvimento de qualquer país, no contexto globalizado, dependeria do plano internacional, porque o "crescente reconhecimento da interdependência das sociedades, [...], leva à necessidade de uma aproximação global dos problemas ligados ao desenvolvimento” (1999, p. 19).

Nesse sentido, a governança global do desenvolvimento apresentou-se como forte tendência no início do século XXI. Sem desconhecer os esforços empreendidos na busca dessa finalidade, particularmente, pela ONU e suas agências especializadas desde a década de 1960, cabe tomar a Declaração do Milênio e seus respectivos Objetivos como ponto de análise, uma vez que o referido itinerário foi o antecessor da Agenda 2030, e contribuiu para a construção da pluridimensionalidade do conceito de desenvolvimento no plano institucional.

Realizada em setembro de 2000, a Cúpula do Milênio resultou na adoção da Declaração do Milênio, compromisso dos 189 países membros da ONU "com as necessidades reais das pessoas de todo o mundo", conforme afirmara o então Secretário-Geral Kofi Annan no prefácio do documento (ONU, 2000, prefácio). Em seu primeiro relatório de acompanhamento da Cúpula, apresentado em 6 de setembro de 2001, o Secretário-Geral informou que, com fundamento na Declaração, um conjunto de Objetivos de Desenvolvimento do Milênio (ODM) havia sido especificado, e, em seguimento, estes Objetivos começaram a ser referidos e utilizados como parte da política e do planejamento da maioria dos membros da ONU (FUKUDA-PARR; HULME, 2009, p. 42).

Os ODM expressaram a prioridade pública geral no período entre 2000 e 2015, e foram sumarizados da seguinte forma: 1) Acabar com a fome e a miséria; 2) Oferecer educação básica de qualidade para todos; 3) Promover a igualdade entre sexos e a autonomia das mulheres; 4) Reduzir a mortalidade infantil; 5) Melhorar a saúde das gestantes; 6) Combater a Aids, a malária e outras doenças; 7) Garantir qualidade de vida e respeito ao meio ambiente; e 8) Estabelecer parcerias para o desenvolvimento (ONU, 2000, n.p). A agenda representou um efetivo método de mobilização global e possibilitou uma delimitação mais estratégica, sobretudo, das ações dos Estados, e, ainda que não apresentasse uma perspectiva de fato integradora e equilibrada 
das diferentes dimensões, encampou elementos sociais, econômicos e ambientais ao tratar do desenvolvimento (SACHS, 2012, p. 2206).

De acordo com o relatório final dos ODM, datado de 2015, "com intervenções direcionadas, estratégias sólidas, recursos adequados e vontade política, mesmo os países mais pobres puderam alcançar progressos sem precedentes" (UN, 2015, p. 4). Apenas para exemplificar, a pobreza extrema foi reduzida significativamente: se em 1990 quase metade da população dos países em desenvolvimento vivia com menos de US \$ 1,25 por dia, essa proporção caiu para $14 \%$ em 2015. Todavia, apesar do sucesso, a realização dos ODM aconteceu de modo díspar entre regiões e países, deixando lacunas significativas, que afetam notadamente a parcela mais vulnerável da sociedade (UN, 2015, p. 8). Para Sachs (2012, p. 2206), "o déficit representa uma série de falhas operacionais, [...] promessas de assistência ao desenvolvimento feitas por países ricos, por exemplo, não te[riam] sido mantidas”.

Por isso, ao final do período de implementação dos ODM, o balanço entre os seus avanços e falhas sugeriu a adoção de uma nova Agenda para o mundo pós-2015. Diferente da anterior, preponderantemente social e econômica e focada em problemas mais expressivos nos países subdesenvolvidos e em desenvolvimento, a nova proposta foi alicerçada no desenvolvimento sustentável e partiu de uma perspectiva capaz de eludir todos os países.

Logo em seu preâmbulo, o documento "Transformando Nosso Mundo: a Agenda 2030 para o Desenvolvimento Sustentável" assinala que os 17 ODS e as 169 metas ali previstos "são integrados e indivisíveis, e equilibram as três dimensões do desenvolvimento sustentável: a econômica, a social e a ambiental" (ONU, 2015, preâmbulo). Uma quarta dimensão, a políticainstitucional, é frequentemente apontada como implícita, uma vez que, em várias passagens da Agenda, há referência à atuação dos atores para a efetivação dos objetivos e metas previstos (SACHS, 2017, p. 502-503).

Vale assinalar que, embora a Agenda 2030 represente o ponto alto da incorporação do conceito pluridimensional de desenvolvimento aos instrumentos da ONU, no meio acadêmico essa construção remete aos anos 1990, com o advento de trabalhos paradigmáticos, como o de Spangenberg (1995). Em obra pouco explorada pela literatura brasileira, o biólogo e economista alemão lançou o triângulo da sustentabilidade, figura cujos vértices, iguais em importância e tamanho, representariam as dimensões ambiental, econômica e social do desenvolvimento sustentável. O desenho do triângulo, porém, foi substituído, na segunda edição do livro, pelo de um prisma, ao perceber-se a conveniência de uma quarta dimensão - a institucional - voltada 
para concretização da sustentabilidade por meio da governança (SPANGENBERG, 1995, p. 3).

Esse giro conceitual implica no reconhecimento de que "o desenvolvimento, segundo entendemos hoje, é um conceito abrangente diferente de crescimento econômico, ainda considerado uma condição, mas de forma alguma suficiente" (SACHS, 1997, p. 213), incluindo muitas dimensões, todas elas sistematicamente interrelacionadas e formando um todo. Ademais, "a natureza processual do desenvolvimento exige, além disso, que se leve em consideração sua sustentabilidade (perenidade) para satisfazer o postulado ético da solidariedade diacrônica com as futuras gerações" (SACHS, 1997, p. 213).

Portanto, é possível conjecturar que o desenvolvimento sustentável pluridimensional restou consagrado como a versão mais contemporânea do próprio conceito de desenvolvimento, opção que parece bastante clara, pelo menos no âmbito da ONU, dada a transição de uma agenda de "objetivos de desenvolvimento" para uma agenda de "objetivos de desenvolvimento sustentável”.

\section{O CONSUMO ENQUANTO VETOR DE DESENVOLVIMENTO SUSTENTÁ VEL}

O abrangente conceito de desenvolvimento sustentável proclamado na Agenda 2030 transforma uma infinidade de questões em alvo da cooperação global, refletindo com mais coerência a complexidade e a interconectividade dos desafios contemporâneos. Entre as variáveis de desenvolvimento sustentável pontuadas no documento, interessa abordar, no escopo deste trabalho, o consumo sustentável, previsto no ODS 12.

O consumo sustentável é tema que interessa à academia e ao meio político desde o início dos anos 1990, quando a concepção de "produção mais limpa $(\mathrm{P}+\mathrm{L})$ ", lançada na década de 1970, passa a considerar os impactos do produto para além daqueles verificados no seu processo produtivo. De acordo com Amaro (2012, n.p), a mudança de foco da "produção mais limpa" para o "consumo sustentável” pode ser aferida, também, em outros três aspectos: a passagem "[...] do consumidor como objeto para o consumidor como agente (consumo responsável); de opiniões antagonistas para parcerias (entre governo, setor produtivo, e sociedade civil); e de regulação para iniciativas voluntárias”.

Nos instrumentos da ONU, a temática foi introduzida com a Agenda 21, adotada na "Rio 92". O capítulo quatro do itinerário, denominado "mudança dos padrões de consumo", apresentava duas áreas programáticas: a) o exame dos padrões insustentáveis de produção e 
consumo, e b) o desenvolvimento de políticas e estratégias nacionais de estímulo a mudança desses padrões (UNCED, 1992, n.p). Na Rio +10, realizada em Johannesburgo, consignou-se a necessidade de um plano de ação em apoio às iniciativas regionais e nacionais preocupadas com a efetivação da Agenda 21, o que ensejou a criação do "Processo de Marrakesh sobre produção e consumo", constituído em torno de sete forças-tarefa de implementação: construção sustentável, produtos sustentáveis, compras públicas sustentáveis, turismo sustentável, estilo de vida sustentável, educação para um consumo sustentável e cooperação com a África (AMARO, 2012, n.p).

Partindo desses antecedentes, a Agenda 2030 estabelece em seu décimo segundo Objetivo: "Assegurar padrões de produção e consumo sustentáveis" (ONU, 2015, p. 31, grifos nossos). As metas que acompanham o preceito preveem, entre outras medidas, o uso eficiente dos recursos naturais; a redução do desperdício de alimentos; o manejo adequado de produtos químicos; a redução da geração de resíduos; o incentivo às empresas para tornarem sustentáveis suas cadeias produtivas; a garantia de informação, visando a conscientização das pessoas, sobre estilos de vida em harmonia com a natureza; a promoção de práticas de compras públicas sustentáveis; e a racionalização dos subsídios destinados aos combustíveis fósseis, que encorajam o consumo exagerado (ONU, 2015, p. 31-32).

Pelo seu caráter normativo, a Agenda não adentra em questões conceituais, circunstância que obriga recorrer a outras fontes para uma definição do que seja o consumo sustentável.

O Programa das Nações Unidas para o Meio Ambiente (PNUMA) define consumo sustentável como o "uso de bens e serviços que atendam às necessidades básicas, proporcionando uma melhor qualidade de vida, enquanto minimizam o uso dos recursos naturais e materiais tóxicos, a geração de resíduos e a emissão de poluentes durante todo o ciclo de vida do produto" (PNUMA, 2014, p. 21). Apesar de seu rico conteúdo, este conceito apresenta limitações, porque explora somente a perspectiva dos impactos ambientais do consumo.

Não é demais lembrar que consumo sustentável não se confunde com consumo verde: o segundo sucede quando o consumidor inclui no seu processo de escolha a variável ambiental, preocupando-se com a agressão ao meio ambiente que o objeto de consumo provocou; o primeiro, por seu lado, e diferentemente, pressupõe um conjunto de variáveis a ser levado em conta no ato da escolha, isto é, "se complexifica e engloba uma quantidade maior de estratégias preocupadas com questões mais amplas, coletivas” (SILVA, 2012, p. 223). 
Nessa senda, parece mais completa a definição de consumo sustentável formulada por Srinivas (2015, n.p) para o Global Development Research Center. Para o autor, consumo sustentável "é o consumo de bens e serviços que têm impacto mínimo sobre o meio ambiente, são socialmente justos e economicamente viáveis, atendendo às necessidades básicas dos seres humanos em todo o mundo", e tendo como alvo todas as pessoas, em todos os setores e países, “[...] desde o indivíduo até governos e conglomerados multinacionais" (SRINIVAS, 2015, n.p).

Stelzer, Todescat e Gonçalves (2016, p. 28) afirmam que os termos "consumo ético", “consumo responsável" e "consumo consciente" denotam, também, outras nuances de sustentabilidade, além da ecológica. Os autores identificam como sustentável o consumo que perpassa pela escolha de produtos "que respeitam os recursos naturais, que amparam os trabalhadores e que estimulam o respeito humano, como a igualdade de gênero, a proibição do trabalho infantil ou de trabalho forçado. Além do mais, estimula-se a aquisição do necessário, sem exageros ou distorções" (STELZER; TODESCAT; GONÇALVES, 2016, p. 28).

Enquanto escolha, o consumo sustentável é ato político. Ao optar-se pela compra de determinado produto, avalizam-se, também, as atitudes e procedimentos que estão por trás de sua produção, distribuição e comercialização. Mascarenhas e Gonçalves (2016, p. 121) adotam esse norte - embora prefiram a expressão "consumo responsável” -, e consideram fundamental despertar a consciência dos consumidores sobre a sua capacidade de contribuir para a transformação social ou favorecer a manutenção de dinâmicas sociais nocivas, por meio do consumo.

Deslocado o estudo para o campo prático, o Instituto Akatu, nos seus "Dez caminhos para a produção e consumo consciente", reforça a existência de variáveis sociais e econômicas no terreno do consumo sustentável. O decálogo elaborado pela organização não-governamental recomenda a opção: a) por produtos duráveis em face dos descartáveis ou de obsolescência acelerada; b) pela produção local em face da produção global; c) pelo uso compartilhado em face da posse e uso individual; d) pelo aproveitamento integral dos produtos em face do desperdício; e) por produtos e formas de viver mais saudáveis; f) pelo virtual em face do material; g) pela suficiência em face do excesso; h) pela experiência e pela emoção em face do que é tangível; i) pela cooperação para a sustentabilidade em face da competição; j) pela publicidade não orientada para o consumismo (INSTITUTO AKATU, 2014, n.p). Na sua simplicidade, as atitudes listadas evidenciam o papel transformador que o ato do consumo pode assumir na construção de uma sociedade sustentável. 
A breve exposição articulada neste tópico, abrangendo os antecedentes do consumo sustentável no contexto da ONU, a sua previsão na Agenda 2030, e, notadamente, a transformação do conceito - que, como observado, guarda simetria com a própria noção de desenvolvimento sustentável, por apresentar uma abordagem pluridimensional -, subsidia a passagem para o última parte do estudo. Nela, serão investigados os signos da sociedade contemporânea de consumidores e enfatizados os limites e as possibilidades da efetivação do consumo sustentável.

\section{DESAFIOS À EFETIVAÇÃO DO CONSUMO SUSTENTÁVEL NA ERA DA LEVEZA}

A par das recomendações da ONU, que indicam não apenas a desejabilidade, mas, também, a necessidade de novos padrões de consumo para viabilizar um modelo de desenvolvimento pluridimensional e sustentável, a análise da sociedade de consumidores contemporânea, a partir das contribuições de importantes sociólogos, ajuda a compreender as reais possibilidades de efetivação desse ideal.

A expressão "sociedade de consumo" popularizou-se no período sucedâneo à Segunda Guerra Mundial, quando o exponencial crescimento econômico, a elevação da produtividade do trabalho e a organização tayloriana-fordista da produção permitiram a emergência do capitalismo de consumo de massa. Pela primeira vez, grandes camadas da população tiveram acesso a bens antes reservados às elites sociais, como o automóvel, a televisão e os aparelhos eletrodomésticos. Nesta nova sociedade, a melhoria das condições de vida transforma-se em “ardorosa obrigação", projeto em torno do qual todos se mobilizam para obter um cotidiano confortável e fácil, sinônimo de felicidade (LIPOVETSKY, 2007, p. 21). "O cosmo moderno se constrói”, portanto, à volta “[...] da ideologia do progresso e de sua promessa de felicidade universal, que nada mais é senão o projeto prometeico de tornar a existência mais leve" (LIPOVETSKY, 2016, p. 39).

Característica da segunda era do capitalismo de consumo - a primeira teria se iniciado por volta dos anos 1880 e terminado no entre guerras -, há quem considere extinta a sociedade do consumo de massa, por conta do advento de um novo tipo de sociedade, resultado da revolução das tecnologias da informação e da comunicação. Para Lipovetsky (2007, p. 14-15), porém, a "saída" da sociedade de consumo não significa o "desconsumo", mas, sim, o 
aprofundamento dessa tendência, a partir de novas prioridades, mas que não deixam de reverberar o consumismo.

Diferentemente do consumo, que é da natureza do indivíduo, o consumismo "é um tipo de arranjo social resultante da reciclagem de vontades, desejos e anseios humanos rotineiros, permanentes e, por assim dizer, neutros ao regime, transformando-os na principal força propulsora e operativa da sociedade" (BAUMAN, 2008, p. 41). O consumismo, conclui o Bauman (2008, p. 41), manifesta-se quando o consumo passa a ocupar o lugar central que na sociedade de produtores era ocupado pelo trabalho. Esse mesmo fenômeno é denominado “hiperconsumo", por Lipovetsky (2016, p. 35), e o elemento característico de sua ocorrência consiste, segundo o autor, no apreço pela mudança e pelo novo, que se difunde em escala universal, deixando em segundo plano as motivações relacionadas à demonstração de status.

Persiste o processo de expansão das necessidades - que, invariavelmente, conduz a exploração excessiva dos recursos naturais para a produção de bens que nem sempre são dotados de utilidade -, mas, agora, o arranjo é diferente. O "consumo ostentativo", que funcionava como artifício para a demarcar uma determinada posição social, cede lugar para o “consumo experiencial”: “queremos objetos 'para viver', mais que objetos 'para exibir', compramos menos isto ou aquilo para nos pavonear, que com vista a satisfações emocionais e corporais, sensoriais e estéticas, relacionais e sanitárias, lúdicas e distrativas" (LIPOVETSKY, 2007, p. 26). Assim se caracteriza a "civilização da leveza”, cunhada por Lipovetsky.

Dentro do cataclisma da busca incessante por novas experiências, e, sobretudo, por prazer, legitima-se a “[...] despreocupação com os dias” (LIPOVETSKY, 2016, p. 41). Isso significa que a coletividade não se mobiliza em torno de objetivos a longo prazo ou de ideologias, porque os sacrifícios que uma vida com propósito exige não fazem frente à possibilidade de um presente lúdica e frivolamente aproveitado. A "ética da satisfação imediata", para usar a expressão de Lipovetsky (2016, p. 2), predominante nesses tempos de leveza, afigura-se como um grande desafio ao cumprimento da Agenda 2030, e, consequentemente das metas de consumo sustentável, uma vez que a realização destas depende da conscientização e, mais do que isso, de uma profunda mudança de hábito dos consumidores.

A feitichização do instante presente é característica da contemporaneidade observada, também, por Bauman. Na afirmação do autor, nada notabiliza mais o "consumismo líquidomoderno" do que a mudança na concepção do tempo: "A vida, seja individual ou social, não passa de uma sucessão de presentes, uma coleção de instantes experimentados com intensidades variadas" (BAUMAN, 2008, p. 46). Essa tendência "agorista" encontra justificativa na pressa 
em adquirir e acumular, mas, principalmente, na necessidade de descartar e substituir, lógica exitosamente propalada pela economia consumista, que prospera graças ao movimento das mercadorias (BAUMAN, 2008, p. 49-51).

O mercado em geral empresta da indústria da moda a estratégia da despadronização dos produtos, e, para terem poder de venda numa sociedade que julga o novo superior ao antigo, as empresas operam sob a lei da constante renovação dos modelos (LIPOVETSKY, 2009, p. 185187). Para ilustrar esse quadro basta observar a ascensão dos sistemas de troca anual de smartphones: invocando a "sensação boa de descobrir algo novo", uma revendedora brasileira da marca Apple anuncia, por exemplo, o seu programa de fidelidade, que garante ao cliente "Iphone novo todo ano" . A efemeridade dos produtos assinala tanto o aumento da demanda por matéria-prima, como o da produção de lixo, conforme atenta Bauman (2008, p. 45), o que implica no crescimento dos impactos ambientais.

Se, como exposto, a leveza do consumo está evidenciada na constante busca pela novidade, no excesso e no desperdício, paradoxalmente, e em paralelo a cenário tal, assiste-se ao nascimento de uma nova tendência. Trata-se da autorrecriminação dos consumidores, que, oprimidos pelo "peso da leveza" de suas práticas, passam a acenar positivamente para outras matrizes de consumo assentadas na ideia de sustentabilidade (LIPOVETSKY, 2016, p. 59-68). A efetivação do consumo sustentável na Agenda 2030 encontra nessa vertente reflexiva algumas possibilidades.

O recuo da frivolidade por parte de uma parcela de consumidores indica o fortalecimento não apenas do consumo ecológico e responsável, mas, também, do consumo colaborativo, pautado pela cooperativa, o empréstimo, o aluguel, a troca e a doação. Essas práticas "que não ignoram o prazer e o lazer, privilegiam, sobretudo, o melhor preço, a otimização dos gastos em razão de novos problemas orçamentários”, e, sob outro vértice, refletem a vontade das pessoas em fazer "[...] algum um gesto pelo planeta, lutar contra o desperdício, ajudar-se mutuamente, recriar um vínculo social” (LIPOVETSKY, 2016, p. 62). O retorno à simplicidade indica, nesse sentido, a aspiração por uma "vida menos pesada", com menos velocidade e menos coisas.

O “neoconsumidor", na asserção de Lipovetsky (2016, p. 59), está revelando a sua faceta vigilante e crítica, de quem se arvora de informações e passa a avaliar os produtos, seus riscos e impactos. Olha com receio, por exemplo, para os alimentos transgênicos e o uso de pesticidas.

\footnotetext{
${ }^{4}$ Programa oferecido por varejista de produtos eletrônicos (https://www.lojaiplace.com.br/sub/refresh), e semelhante ao “Apple Upgrade Program”, existente nos Estados Unidos.
} 
Para ele, ato da compra requer "uma atualização dos conhecimentos, das comparações e escolhas 'esclarecidas': estamos no momento da reflexão consumista que, ao transformar o consumo em problema, faz dele um objeto de preocupação e dúvida” (LIPOVETSKY, 2016, p. $59)$.

A crescente adesão ao Comércio Justo também sinaliza essas mudanças. Em 2009, a procura por produtos de Comércio Justo certificados pela Fair Trade International aumentou em $15 \%$, comparado ao ano de 2008, atingindo um total de 3,4 bilhões de euros, em vendas no varejo. Foram comercializados aproximadamente 27 mil produtos com o selo de Comércio Justo, em mais de 70 países, e o reconhecimento do selo ultrapassava $80 \%$ em alguns países (SCHNEIDER, 2012, p. 49).

O grande aporte do Comércio Justo ao consumo sustentável reside no fato de que, por meio dele, o consumidor não adquire apenas produtos, mas relações de compromisso com os produtores. Está disposto a pagar o preço que cobre os custos de um "[...] rendimento digno, ambientalmente responsável e socialmente inclusivo" (STELZER; TODESCAT; GONÇALVES, 2016, p. 20), consoante, portanto, com a própria noção de desenvolvimento sustentável pluridimensional.

Não obstante, ainda que as evoluções indicadas na segunda parte do presente tópico sejam importantes para o alcance do consumo sustentável, Lipovetsky (2016, p. 69) considera que são reduzidas as chances de que elas promovam o fim da "atração pelo Novo" e o surgimento de uma cultura pós-consumista. Atenta ele: "Por muito tempo ainda, e qualquer que sejam seus desvios, a busca pelo alívio da existência passará pelo consumismo, por seus prazeres, e, paradoxalmente, por seu peso crescente" (LIPOVETSKY, 2016, p. 70).

Assim, no horizonte da realização da Agenda 2030 da ONU, especificamente quanto ao Objetivo e metas de consumo sustentável, avistam-se possibilidades, as quais são limitadas pelos próprios elementos conformadores da sociedade de consumo contemporânea, ou, para utilizar, a expressão de Lipovetsky, da civilização da leveza.

\section{CONCLUSÃO}

O presente estudo investigou as perspectivas de efetivação do consumo sustentável, um dos Objetivos de Desenvolvimento Sustentável elencados pela ONU, a partir do diagnóstico da sociedade contemporânea empreendido, especialmente, pelo olhar crítico de Gilles Lipovetsky. 
Como se observou, a ideia originária de desenvolvimento, enquanto mero crescimento econômico, passou por acentuadas transformações nas últimas décadas, ganhando forma e preponderando, pelo menos no plano do sistema da ONU, uma nova abordagem do fenômeno, mais ampla e complexa. Ela reconhece a confluência de aspectos sociais, econômicos, ambientais e político-institucionais, permeados pelo atributo da sustentabilidade no tempo, para a formação de um conceito de desenvolvimento sustentável pluridimensional. Esse novo paradigma encontra na Agenda 2030 instrumento de governança global para o período 20152030, com sua máxima expressão no campo do sistema da ONU.

Dentro do extenso rol de variáveis de desenvolvimento sustentável pluridimensional previsto na Agenda, mereceu destaque, no âmbito deste estudo, o consumo sustentável. Previsto no ODS 12, implementá-lo significa adotar práticas de consumo que acarretem mínimo impacto sobre o meio ambiente, e sejam socialmente justas e economicamente viáveis. Para chegar lá, o plano de ação da ONU assinala a urgência da conscientização sobre a necessidade de estilos de vida em harmonia.

A realização desse pressuposto, no entanto, encontra limites na própria tessitura social contemporânea, cujos valores do consumismo, do apreço pelo novo, pelo excesso e desperdício, e da despreocupação com as questões que ultrapassam a esfera individual, predominam. De encontro e em reação à lógica da leveza, emergem tendências como o consumo ecológico, o comércio justo e o consumo compartilhado, que, embora pouco expressivas e isoladas, representam possibilidades para a efetivação do consumo sustentável que não podem ser ignoradas.

\section{REFERÊNCIAS}

AMARO, Meiriane Nunes. Como obter produção e consumo sustentáveis? Disponível em:http://www.brasil-economia-governo.org.br/wpcontent/uploads/2

012/07/como-obter-producao-e-consumosustentaveis.pdf. Acesso em: 20 abr. 2019.

BAUMAN, Zygmunt. Vida para consumo: a transformação das pessoas em mercadoria. Tradução Carlos Alberto Medeiros. Rio de Janeiro: Jorge Zahar Ed., 2008.

CRESWELL, John W. Projeto de pesquisa: métodos qualitativo, quantitativo e misto. Tradução Magda França Lopes. 3. ed. Porto Alegre: Artmed, 2010.

DA VEIGA, José Eli. O prelúdio do desenvolvimento sustentável. In: MERCADANTE, Aloizio et al. (org.). Economia brasileira: Perspectivas do desenvolvimento. São Paulo: CAVC, 2005. p. 243-266. Disponível em: https://edisciplinas.usp.br/mod/resource/view.php?id=88617. Acesso em: 10 abr. 2019. 
DRESNER, Simon. The principles of sustainability. New York: Routledge, 2002.

FUKUDA-PARR, Sakiko; HULME, David. International Norm Dynamics and "the End of Poverty": Understanding the Millennium Development Goals (MDGs). Brooks World Poverty Institute: Manchester, junho de 2009. Disponível em:

http://citeseerx.ist.psu.edu/viewdoc/download?doi=10.1.1.469.4684\&rep=rep1\&type=pdf. Acesso em: 14 abr. 2019.

FURTADO, Celso. O mito do desenvolvimento econômico. 2. ed. Rio de Janeiro: Paz e Terra, 1974.

INSTITUTO AKATU. 10 caminhos para a produção e consumo conscientes. 2014. Disponível em: https://www.akatu.org.br/noticia/10-caminhos-para-producao-consumoconscientes/. Acesso em: 22 abr. 2019.

LIPOVETSKY, Gilles. A felicidade Paradoxal: ensaio sobre a sociedade do hiperconsumo. Tradução de Maria Lucia Machado. São Paulo: Companhia das Letras, 2007.

LIPOVETSKY, Gilles. Da leveza: rumo a uma civilização sem peso. Tradução Idalina Lopes. Barueri-SP: Manole, 2016.

LIPOVETSKY, Gilles. O império do efêmero: a moda e seu destino nas sociedades modernas. Tradução de Maria Lucia Machado. São Paulo: Companhia das Letras, 2009.

MASCARENHAS, Thais; GONÇALVES, Juliana. Grupos de consumo sustentável: práticas de consumidores baseadas no comércio justo e solidário. In: STELZER, Joana; GOMES, Rosemary (Orgs.). Comércio Justo e Solidário no Brasil e na América Latina.

Florianópolis: Departamento de Ciências da Administração/UFSC, 2016. p. 119-140.

ORGANIZAÇÃO DAS NAÇÕES UNIDAS. Declaração do Milênio. 2000. Disponível em:http://www.br.undp.org/content/brazil/pt/home/library/ods/declar acao-do-milenio.html. Acesso em: 22 abr. 2019.

ORGANIZAÇÃO DAS NAÇÕES UNIDAS. Transformando Nosso Mundo: a Agenda 2030 para o Desenvolvimento Sustentável. 2015. Disponível em: http://www.br.undp.org/cont ent/dam/brazil/docs /agenda2030/undp-br-Agenda2030-completo-pt-br 2016.pd f. Acesso em: 10 abr. 2019.

PERRONE-MOISÉS, Cláudia. Direitos humanos e desenvolvimento: a contribuição das Nações Unidas. In: AMARAL JÚNIOR, Alberto do; PERRONE-MOISÉS, Cláudia (Orgs.). O cinquentenário da Declaração Universal dos Direitos do Homem. São Paulo: EdUsp, 1999. p. 179-196.

PIOVESAN, Flávia. Direito ao desenvolvimento: desafios contemporâneos. In: PIOVESAN, Flávia; SOARES, Inês Virgínia Prado (orgs.). Direito ao desenvolvimento. Belo Horizonte: Fórum, 2010. p. 95-116.

PROGRAMA DAS NAÇÕES UNIDAS PARA O MEIO AMBIENTE. Guia da produção e consumo sustentáveis: tendências e oportunidades para o setor dos negócios. 2014. 
Disponível em: https://nacoesunidas.org/wp-content/uploads/2015/06/PNUMA_Guia-deProdu\%C3\%A7\%C3\%A3o-e-Consumo-Sustent\%C3\%A1 veis.pdf. Acesso em: 20 abr. 2019.

SACHS, Jeffrey D. From Millennium Development Goals to Sustainable Development Goals. The Lancet, [S.1], v. 379, n. 9832, p. 2206-2211, 2012. Disponível em:

http://www.thelancet.com/journals/lancet/article/PIIS0140-6736(12)60685-0/abstract. Acesso em: 25 abr. 2019.

SACHS, Ignacy. Caminhos para o desenvolvimento sustentável. Rio de Janeiro: Garamond, 2009.

SACHS, Ignacy. Desenvolvimento numa economia mundial liberalizada e globalizante: um desafio impossível? Estudos Avançados, São Paulo, v. 11, n. 30, p. 213-242, 1997. Disponível em: http://www.scielo.br/scielo.php?pid=S010340141997000200014\&script=sci arttext\&tlng=es. Acesso em: 16 abr. 2019.

SCHNEIDER, Johann. Relatório da pesquisa mundial de comércio justo: parte 2. Brasília: SEBRAE, 2012. Disponível em: http://base.socioeco.org/docs/nt0004733a.pdf. Acesso em: 15 abr. 2019.

SILVA, Minelle Enéas da. Consumo sustentável: a articulação de um constructo sob a perspectiva do desenvolvimento sustentável. Revista Eletrônica de Ciências Administrativas, Campo Largo, v. 11, n. 2, p. 217-232, 2012. Disponível em:http://www.periodicosibepes.org.br/index.php/recadm/article/view/1052/675. Acesso em: 20 abr. 2019.

SPANGENBERG, Joachim H. (ed.). Towards sustainable Europe: a study from the Wuppertal Institute for Friends of the Earth Europe. Luton/Bruxelas: FoE Publications, 1995.

SRIVINAS, Hari. Sustainability concepts: sustainable consumption. GDRC Research. Kobe, Japan: Global Development Research Center. Disponível em:

http://www.gdrc.org/sustdev/concepts/22-s-consume.html. Acesso em: 18 abr. 2019.

STELZER, Joana; TODESCAT, Marilda; GONÇALVES, Everton das Neves. O projeto Ilha Rendada e o Comércio Justo: princípios normativos, práticas e desafios. In: STELZER, Joana; GOMES, Rosemary (Orgs.). Comércio Justo e Solidário no Brasil e na América Latina. Florianópolis: Departamento de Ciências da Administração/UFSC, 2016. p. 19-54.

UNITED NATIONS CONFERENCE ON ENVIRONMENT \& DEVELOPMENT. Agenda 21. Rio de Janeiro, 1992. Disponível em:https://sustainabledevelopment.un.org /content/documents/Agenda21.pdf. Acesso em: 17 abr. 2019.

UNITED NATIONS. The Millennium Development Goals Report 2015. 2015. Disponível em: https://nacoesunidas.org/wp-content/uploads/2015/07/MDG-2015-June-25.pdf. Acesso em: 14 abr. 2019. 